\title{
Female Breast Cancer in Lombardy, Italy (2002-2009): A Case-Control Study on Occupational Risks
}

\author{
Enrico Oddone, $\mathrm{MD},{ }^{1 *}$ Valeria Edefonti, $\mathrm{PhD},{ }^{2}$ Alessandra Scaburri, $\mathrm{ScD},{ }^{3}$ \\ Tiziana Vai, MD, ${ }^{4}$ Paolo Crosignani, MD, ${ }^{3}$ and Marcello Imbriani, MD $^{5}$
}

\begin{abstract}
Background The role of occupational exposures in breast cancer development is still uncertain and to our knowledge, no studies have been recently carried out in Italy to provide a comprehensive estimation of this possible risk.

Methods Based on administrative data, a case-control study was carried out recruiting all incident cases of female breast cancer in the period 2002-2009, aged between 35 and 69 years, residing in Lombardy, Italy. Controls were randomly sampled from all women residing in Lombardy as of December 31, 2005. Occupational histories, including bluecollar status, were available from 1974 through record linkage with a social security pension database, and were obtained for 11,188 cases and 25,329 controls. Adjusted odds ratios (ORs) and corresponding $90 \%$ confidence intervals (CIs) were calculated using multiple unconditional logistic regression models, including terms for sectors of longest employment and for duration of employment. Multiple comparisons were accounted for according to the Benjamini-Hochberg method.

Results The ORs for female breast cancer were modestly but significantly increased for employment in electrical manufacturing (OR 1.12, 90\%CI 1.04-1.21), textile (OR 1.08, 90\%CI 1.02-1.15), paper (OR 1.25, 90\% CI 1.06-1.46) and rubber (OR 1.26, 90\% CI 1.031.54) industries. Analysis by duration of employment within sectors showed significantly increased ORs for electrical manufacturing and rubber industries. After adjustment for multiple comparisons no estimates remained statistically significant.

Conclusions Although with several limitations, our results point to a possible role of exposures in electrical manufacturing, textile, paper and rubber industries in the process leading to breast cancer. An in-dept study for the electrical manufacturing industry has been already planned. Am. J. Ind. Med. 2013. () 2013 Wiley Periodicals, Inc.
\end{abstract}

KEY WORDS: breast cancer; occupational exposures; electrical manufacturing; casecontrol study; OCCAM project

${ }^{1}$ Department of Public Health, Experimental and Forensic Medicine, University of Pavia, Pavia, Italy

${ }^{2}$ Departement of Clinical Sciences and Community Health, Università degli Studi di Milano, Milan, Italy

${ }^{3}$ Foundation IRCCS Istituto dei Tumori, Cancer Registry and Environmental Epidemiology Unit, Milan, Italy

${ }^{4}$ Local Health Unit, SS UOPSAL 3, Milan, Italy

${ }^{5}$ Department of Public Health, Experimental, and Forensic Medicine, University of Pavia, Pavia, Italy

Contract grant sponsor: INAIL, Italian National Occupational Insurance Institute. Contract grant sponsor: Italian Ministry of Education; Contract grant number: INAIL 120
H 67; Contract grant sponsor: Italian Ministry of Education; Contract grant number:PRIN $2009 \times 84$ CBN.

Disclosure Statement:The authors report no conflicts of interests.

*Correspondence to: Dr. Enrico Oddone, Department of Public Health, Experimental and Forensic Medicine, University of Pavia,Via Severino Boezio 24, 27100 Pavia, Italy. E-mail:enrico.oddone@unipv.it

Accepted11 April 2013

DOl 10.1002/ajim.22205. Published online in Wiley Online Library (wileyonlinelibrary.com). 


\section{INTRODUCTION}

Female breast cancer has several well-known risk factors. Referring to breast cancer, the International Agency for Research on Cancer (IARC) classifies as "carcinogenic to humans" (Group 1) alcoholic beverages, exposures to diethylstilbestrol, estrogen-progestogen contraceptives, estrogen-progestogen hormone replacement therapy, exposures to X-radiation and gamma-radiation and, although with limited evidence in epidemiologic studies, ethylene oxide [IARC, 1987, 1999, 2002, 2003, 2012; Grosse et al., 2009; Secretan et al., 2009]. Among reproductive factors, early age at menarche, late age at menopause, nulliparity and age at first full-term pregnancy above 30 years are considered as risk factors, as well as lack of physical activity and obesity in postmenopausal women. The presence of a family history of hormone-related cancers and mutations in the BRCA-1 and BRCA-2 genes are also associated with an increased risk of breast cancer [Weiderpass et al., 2011].

Despite much interest in the role of genetic predisposition, only a small proportion of breast cancer cases are explained by genetic variants [Davis et al., 1998]. Moreover, breast cancer incidence has steadily increased during recent decades in industrialized countries, while in emerging economies where it was traditionally low; it has increased with industrialization [Jemal et al., 2010]. Also, women who have migrated from low-incidence countries to highincidence ones show a breast cancer incidence similar to that of the host country [Ziegler et al., 1993]. These observations suggest that environmental factors in a broad sense play an important role in breast cancer.

In this context, occupational exposures are good candidates for investigation. Previous findings suggest that chemical substances, industrial processes or some forms of work organization may play a role in the multistage developmental process leading to cancer. In details, there is evidence for a possible role of exposures to acrylic fibers, nylon fibers, monoaromatic, and polycyclic aromatic hydrocarbons and organic solvents in the causation of breast cancer [Labrèche et al., 2010]. Moreover, the occupational attributable fraction for female breast cancer was estimated to be over $4 \%$ in Great Britain, leading to a considerable cancer burden; mostly due to night shift work [Rushton et al., 2010]. Recently, Denmark became the first country to designate breast cancer as an occupational disease eligible for receiving compensation [Commentary, 2009].

Although research on potential occupational risks in industrial sectors with chemical exposures, (such as the textile and garment, rubber and mechanical manufacturing industries) could be relevant to prevention, there are only a limited number of studies devoted to identifying them. To our knowledge, no studies have been carried out in Italy to provide risk estimates of breast cancer for several different occupational sectors.
Based on these considerations, we carried out a study to fully explore the association between employment by industrial sectors classified in the framework of the OCCAM (Occupational CAncer Monitoring) project [Crosignani et al., 2006] and female breast cancer risk, using a population-based case-control study approach.

\section{MATERIAL AND METHODS \\ Overview of the Study}

The OCCAM project monitors cancers potentially due to occupational exposures, based on the collaboration between the former Italian National Institute for Occupational Health (ex-ISPESL) and the National Cancer Institute of Milano. The project started in 2000 , in the setting of the Italian Occupational Safety Act (legislative decrees 626/1994 and $81 / 2008$ ). Its aim is to detect potential occupational cancer cases by identifying associations between employment by industry and cancer occurrence. A record linkage is carried out between the regional databases of hospital discharge records, through which cancer cases are identified, and the archives of pension funds at the National Institute for Social Security (INPS), which records the occupational history of every person who worked in private enterprises since 1974. This approach has been used to conduct several populationbased case-control studies [Aiani et al., 2011; Panizza et al., 2012] and may be used to analyze virtually any association between trades and cancer sites [Crosignani et al., 2006].

For the present study, we recruited all incident cases of female breast cancer in the period 2002-2009 aged between 35 and 69 years at diagnosis, residing in Lombardy, Italy. Controls were randomly sampled from all women residing in Lombardy as of December 31, 2005. We identified 44,486 eligible cases and 92,292 controls. The record linkage with the INPS archive was successful for 25,254 (56.8\%) cases and $53,095(57.5 \%)$ controls. We further restricted our analysis to women who worked as "blue collar," as directly defined in the INPS database. Therefore 11,188 (44.3\% of women with a successful link with INPS files) cases and $25,329(47.7 \%)$ controls were included in the analyses and contributed to the estimates of odds ratios (ORs) of breast cancer and corresponding confidence intervals (CIs) by industrial sector. Details are presented in the following.

\section{Recruitment of Cases and Controls}

Cases were women discharged during the period 20022009 with a diagnosis of incident breast cancer (International Classification Of Diseases (ICD), IX rev.: 174) and with no diagnosis of breast cancer in the period 1999-2001, as identified according to the Lombardy hospital discharge 
records. This exclusion was applied to remove prevalent cases, which might possibly have been included in the administrative dataset.

In Italy both public and private hospitals are obliged to provide individual, codified discharge records. For each patient, hospital discharge records provide the Italian social security number, place of residence, up to six diagnostic ICD codes, and date of discharge. These hospital discharge records are stored in databases according to patients' region of residence, irrespective of hospital location.

Cases older than 69 years were not included in the analysis. Since information on their employment history is available only from 1974, older subjects would potentially end up with too short employment histories for a meaningful analysis. Women younger than 35 years were also excluded because of the potential small number of expected cases.

Controls were extracted from the regional list of citizens registered with the National Health Service as of December 31,2005 . They are therefore a sample of all women residing in Lombardy at that date, as the National Health Service files include almost all residents. Among those subjects, the OCCAM method is designed to select a subset of women through random sampling based on the number of cases. The lower the number of cases, the greater the number of sampled controls, according to the scheme in Table I. The sampling is always made before the record linkage with INPS database. Therefore, we sampled two controls for each case, with an over sampling of $5 \%$, and considering province of residence and 5-year age classes.

\section{Occupational Data Collection}

Employment histories, including company name, industry code, and period(s) of employment, were obtained by a record linkage of the database of cases and controls with the INPS files of pension fund payments, available from private companies from 1974. The linkage key was the Italian social security code, generated from the name, surname, sex, date, and place of birth of each individual in Italy. According to the

TABLE I. Control Sampling Scheme for the Studies Based on the Occupational Cancer Monitoring (OCCAM) Project

\begin{tabular}{lcc}
$\begin{array}{l}\text { Number of incident } \\
\text { cases }\left(\mathbf{N}_{\text {IC }}\right)\end{array}$ & $\begin{array}{c}\text { Sampling } \\
\text { proportion }\end{array}$ & $\begin{array}{c}\text { Number of } \\
\text { controls }\end{array}$ \\
\hline $0-20$ & $10: 1$ & $\mathrm{~N}_{\text {IC }} \times 10$ \\
$21-40$ & $8: 1$ & $\mathrm{~N}_{\text {IC }} \times 8$ \\
$41-50$ & $7: 1$ & $\mathrm{~N}_{\text {IC }} \times 7$ \\
$51-60$ & $5: 1$ & $\mathrm{~N}_{\text {IC }} \times 5$ \\
$61-100$ & $4: 1$ & $\mathrm{~N}_{\text {IC }} \times 4$ \\
$101-200$ & $3: 1$ & $\mathrm{~N}_{\text {IC }} \times 3$ \\
$200+$ & $2: 1$ & $\mathrm{~N}_{\text {IC }} \times 2$ \\
\hline
\end{tabular}

OCCAM protocol, INPS classification of the economic activities (Codice Statistico Contributivo) was converted into ATECO 81 (i.e., Italian statistical classification of economic activities), a classification derived from the statistical classification of economic activities provided by the European community (Nomenclature statistique des activités économiques dans la Communauté européenne, NACE) Revision 1. ATECO 81 is very detailed, which helps to avoid lumping together different trades, but may lead to have several categories with a small number of study subjects each. ATECO 81 categories of industrial activities were then grouped into broader categories (e.g., textile industry), by specialists in occupational medicine (PC, EO, TV). This led to an OCCAM coding system including 49 industrial sectors to be investigated.

For instance, flight transport and private health care services were entered into the "transport" and "health care and veterinarian services" categories respectively, while vehicle manufacturing was entered into the "mechanical manufacturing" sector.

INPS pension fund files themselves provided information on white or blue-collar status for each workers. We used this information to restrict our analysis to the "blue collars" only, as we believe that "blue collar" workers are more likely to be exposed to carcinogens than the corresponding "white collar" ones employed in the same OCCAM coded economic activities.

A "blue collar" worker then was considered as "exposed" if employed in a productive sector for at least 1 year from 1974 to 2009 .

A "blue collar" worker was considered as "unexposed" (reference category) if employed for at least 1 year in services and retail or wholesale trade sectors from 1974 to 2009.

The longest period of employment was used to define the exposure when an individual was employed in different trades.

\section{Statistical Analysis}

Odds ratios (ORs) of breast cancer and corresponding $90 \%$ confidence intervals (CIs) were estimated using unconditional multiple logistic regression models for the overall region and for the single provinces contributing cases to the productive sectors of interest. Adjustment variables were age (5-year classes) and province of residence (categories shown in Table II), when appropriate. Investigated exposures of interest were: ever employment (never/ever) for those sectors with a minimum duration of 1 year, ever employment (never/ever) in the sector of longest duration (minimum duration of 1 year), duration of employment (in continuum, every 1 or 5 years, minimum duration of 1 year), duration of employment (in categories, 4 classes, minimum duration of 1 year). We conducted an extra analysis based on 
TABLE II. Distribution by Province and 5-Year Age Class ${ }^{\mathrm{a}}$ of Breast Cancer Cases and Controls, Before and After Linking DataWith the Italian National Institute for Social Security (INPS) Archive, Lombardy, Italy 2002-2009

\begin{tabular}{|c|c|c|c|c|c|c|}
\hline & \multicolumn{3}{|c|}{ Before INPS database linkage } & \multicolumn{3}{|c|}{ After INPS database linkage } \\
\hline & Breast cancer cases (\%) & Controls (\%) & All (\%) & Breast cancer cases (\%) & Controls (\%) & All (\%) \\
\hline \multicolumn{7}{|l|}{ Province } \\
\hline Bergamo & $4,164(9.4)$ & $8,328(9.0)$ & $12,492(9.1)$ & $2,326(9.2)$ & $4,660(8.0)$ & $6,986(8.9)$ \\
\hline Brescia & $5,687(12.8)$ & $11,374(12.3)$ & $17,061(12.5)$ & $2,889(11.4)$ & $6,026(11.3)$ & $8,915(11.4)$ \\
\hline Como & $2,581(5.8)$ & $5,292(5.7)$ & $7,873(5.8)$ & $1,488(5.9)$ & $2,989(5.6)$ & $4,477(5.7)$ \\
\hline Cremona & $1,695(3.8)$ & $3,669(4.0)$ & $5,364(3.9)$ & $859(3.4)$ & $1,968(3.7)$ & $2,827(3.6)$ \\
\hline Lecco & $1,509(3.4)$ & $3,322(3.6)$ & $4,831(3.5)$ & $808(3.2)$ & $1,886(3.6)$ & $2,694(3.4)$ \\
\hline Lodi & $999(2.2)$ & $2,968(3.2)$ & $3,967(2.9)$ & $579(2.3)$ & $1,745(3.3)$ & $2,324(3.0)$ \\
\hline Milano & $18,794(42.2)$ & $37,588(40.7)$ & $56,382(41.2)$ & $11,215(44.4)$ & $22,436(42.3)$ & $33,651(43.0)$ \\
\hline Mantova & $1,965(4.4)$ & $4,264(4.6)$ & $6,229(4.6)$ & $1,077(4.3)$ & $2,538(4.8)$ & $3,615(4.6)$ \\
\hline Pavia & $2,407(5.4)$ & $4,916(5.3)$ & $7,323(5.4)$ & $1,372(5.4)$ & $2,775(5.2)$ & $4,147(5.3)$ \\
\hline Sondrio & $753(1.7)$ & $2,512(2.7)$ & $3,265(2.4)$ & $339(1.3)$ & $1,289(2.4)$ & $1,628(2.1)$ \\
\hline Varese & $3,932(8.8)$ & $8,059(8.7)$ & $11,991(8.8)$ & $2,302(9.1)$ & $4,783(9.0)$ & $7,085(9.0)$ \\
\hline All & $44,486(100)$ & $92,292(100)$ & $136,778(100)$ & $25,254(100)$ & $53,095(100)$ & $78,349(100)$ \\
\hline \multicolumn{7}{|l|}{ Age (years) } \\
\hline $35-39$ & $2,037(4.6)$ & $5,359(5.8)$ & $7,396(5.4)$ & $1,523(6.0)$ & $3,924(7.4)$ & $5,447(7.0)$ \\
\hline $40-44$ & $4,430(10.0)$ & $9,624(10.4)$ & $14,054(10.3)$ & $3,271(13.0)$ & $6,908(13.0)$ & $10,179(13.0)$ \\
\hline $45-49$ & $6,259(14.1)$ & $12,767(13.8)$ & $19,026(13.9)$ & 4,768 (18.9) & $9,579(18.0)$ & $14,347(18.3)$ \\
\hline $50-54$ & 6,657 (15.0) & $13,594(14.7)$ & $20,251(14.8)$ & 4,704 (18.6) & $9,802(18.5)$ & $14,506(18.5)$ \\
\hline $55-59$ & $7,393(16.6)$ & $15,058(16.3)$ & $22,451(16.4)$ & $4,134(16.4)$ & $8,726(16.4)$ & $12,860(16.4)$ \\
\hline $60-64$ & $8,604(19.3)$ & $17,334(18.8)$ & $25,938(19.0)$ & $3,713(14.7)$ & 7,667 (14.4) & $11,380(14.5)$ \\
\hline $65-69$ & $9,106(20.5)$ & $18,556(20.1)$ & $27,662(20.2)$ & 3,141 (12.4) & $6,489(12.2)$ & $9,630(12.3)$ \\
\hline All & $44,486(100)$ & $92,292(100)$ & $136,778(100)$ & $25,254(100)$ & $53,095(100)$ & $78,349(100)$ \\
\hline
\end{tabular}

${ }^{\mathrm{a} A g e}$ at diagnosis or sampling.

5 years and 10 years of lag time. Exposures by sector were entered into the regression models alone (single-exposure model) or simultaneously (composite model).

For all the models on duration of employment we carried out an extra adjustment for latency. For all the models including duration in categories, we calculated the $P$-value for linear trend.

For all levels of analysis, we accounted for the problem of multiple comparisons by adding " $q$-values" calculated referring to the Benjamini-Hochberg method [Benjamini and Hochberg, 1995]. We also carried out alternative adjustments for multiple comparisons [Shaffer, 1995; Benjamini and Yekutieli, 2001], to check for our results.

Calculations were performed using SAS software (version 9; SAS Institute Inc., Cary, NC) and the open-source statistical computing environment $\mathrm{R}$ [ $\mathrm{R}$ language 2011].

Studies based on the OCCAM project used administrative data routinely collected by institutional subjects authorized by the Italian law on occupational safety (D. Lgs 81/08, art. 244). Therefore such studies do not require approval from an institutional review board. No direct contact was established with women included in the analyses and therefore no written informed consent was obtained.

\section{RESULTS}

The total number of women potentially involved in our study included 44,486 breast cancer cases and 92,292 controls, giving a total of 136,778 women. The procedure for matching data obtained from hospital discharge records and National Health Service archives with the INPS database was successful for 25,254 (56.8\%) cases and 53,095 (57.5\%) controls. Their distribution by age class and province is shown in Table II.

The blue-collar women set included 11,188 breast cancer cases (44.3\% of women with successful link with INPS files) and 25,329 (47.7\%) controls. Their distribution by age class and province is shown in Table III. The mean age of cases was 53.0 years and that of the controls was 52.7 years.

Cases and controls did not show significant differences in age and residence area. Milano province had the highest number of cases and controls, followed by Brescia and Bergamo.

Table IV shows adjusted ORs of female breast cancer and corresponding $90 \%$ CIs by longest employment industrial sector, obtained from a composite statistical model including all the sectors simultaneously, together with age and province 
TABLE III. Distribution by Province and 5-Years Age Class ${ }^{\mathrm{a}}$ of Blue-Collar Women Included in the Analysis, Lombardy, Italy, 2002-2009

\begin{tabular}{|c|c|c|c|}
\hline & Breast cancer cases (\%) & Controls (\%) & All (\%) \\
\hline \multicolumn{4}{|l|}{ Province } \\
\hline Bergamo & $1,304(11.7)$ & $2,708(10.7)$ & $4,012(11.0)$ \\
\hline Brescia & $1,552(13.9)$ & $3,384(13.4)$ & $4,936(13.5)$ \\
\hline Como & $698(6.2)$ & $1,532(6.0)$ & $2,230(6.1)$ \\
\hline Cremona & $415(3.7)$ & $1,002(4.0)$ & $1,417(3.9)$ \\
\hline Lecco & $429(3.8)$ & $964(3.8)$ & $1,393(3.8)$ \\
\hline Lodi & $251(2.2)$ & $781(3.1)$ & $1,032(2.8)$ \\
\hline Milano & $4,076(36.4)$ & $9,051(35.7)$ & $13,127(35.9)$ \\
\hline Mantova & $518(4.6)$ & $1,314(5.2)$ & $1,832(5.0)$ \\
\hline Pavia & $572(5.1)$ & $1,295(5.1)$ & $1,867(5.1)$ \\
\hline Sondrio & $150(1.3)$ & $673(2.7)$ & $823(2.3)$ \\
\hline Varese & $1,223(10.9)$ & $2,625(10.4)$ & $3,848(10.5)$ \\
\hline All & $11,188(100)$ & $25,329(100)$ & $36,517(100)$ \\
\hline \multicolumn{4}{|l|}{ Age (years) } \\
\hline $35-39$ & $596(5.3)$ & $1,708(6.7)$ & $2,304(6.3)$ \\
\hline $40-44$ & $1,309(11.7)$ & $3,003(11.9)$ & $4,312(11.8)$ \\
\hline $45-49$ & $1,814(16.2)$ & $4,019(15.9)$ & $5,833(16.0)$ \\
\hline $50-54$ & $1,970(17.6)$ & $4,379(17.3)$ & $6,349(17.4)$ \\
\hline $55-59$ & $1,873(16.7)$ & $4,268(16.9)$ & $6,141(16.8)$ \\
\hline $60-64$ & $1,815(16.2)$ & $4,173(16.5)$ & $5,988(16.4)$ \\
\hline $65-69$ & $1,811(16.2)$ & $3,779(14.9)$ & $5,590(15.3)$ \\
\hline All & $11,188(100)$ & $25,329(100)$ & $36,517(100)$ \\
\hline
\end{tabular}

${ }^{\mathrm{a}}$ Age at diagnosis or sampling.

of residence. The ORs for female breast cancer were modestly but significantly increased in women whose longest duration of employment (never/ever exposed) was in the electrical manufacturing, textile, garment, paper or rubber industries. These results were consistent with those from the corresponding models including each sector at a time, which produced increased ORs in the electrical manufacturing $(\mathrm{OR}$ $1.13,90 \%$ CI $1.04-1.22$ ), textile (OR $1.08,90 \%$ CI $1.01-$ 1.15 ), paper (OR $1.25,90 \%$ CI 1.06-1.46) and rubber (OR $1.26,90 \%$ CI 1.03-1.54) industries (data not shown).

Similar results emerged also in the model considering ever employment in single industrial sectors, with slightly increased ORs in the electrical manufacturing (OR 1.11,90\% CI 1.04-1.18), textile (OR 1.07, 90\% CI 1.01-1.12) and paper (OR 1.20, 90\% CI 1.05-1.37) industries, although, for rubber industry, results were of borderline significance (OR $1.11,90 \%$ CI 0.94-1.31) (data not shown). These results were also consistent with those from stratified analyses by province, especially for the Milano province where the number of cases and controls was the highest (data not shown).

After adjustment for multiple comparisons, the corresponding $q$-values were no longer smaller than 0.05 .

Table V shows the ORs of female breast cancer and corresponding $90 \%$ CIs by duration of employment (in categories) in the available industrial sectors, as derived from a composite model adjusted for age, province of residence and latency. This analysis showed increased ORs in the garment industry for $20+$ year class, in electrical manufacturing in the 10-19 and $20+$ year classes and in the rubber industry for all classes. Only electrical manufacturing showed a significant trend in risk by duration of exposure.

Analyses on duration in continuum ( 1 and 5 years) showed increased ORs only in electrical manufacturing (OR $1.01,90 \%$ CI $1.00-1.02$; OR $1.05,90 \%$ CI $1.01-1.08$, respectively) (data not shown).

Using 5- and 10-years of lag time, results (not shown) were still consistent with the previous findings, showing increased ORs in the electrical manufacturing, garment and rubber industries (data not shown). Specifically, in the 5 years lagged duration analysis, increased ORs emerged in the 10 19 year and $20+$ year classes for electrical manufacturing (OR 1.40, 90\% CI 1.11-1.75; OR 1.36, 90\% CI 1.08-1.69, respectively); in the 5-9 years and $20+$ years classes for rubber industry (OR 2.82, 90\% CI 1.23-6.44; OR 2.55, 90\% CI 1.17-5.55, respectively); and only in the $20+$ years class for garment industry (OR 1.17, 90\% CI 1.01-1.35). The textile industry showed a borderline result (OR $1.12,90 \% \mathrm{CI}$ $0.97-1.28$ ).

Results from the 10 years lagged duration analysis were very similar to those from the 5 year lagged duration analysis. 
TABLE IV. Adjusted Odds Ratios $(\mathrm{ORs})^{\mathrm{a}}$ of Breast Cancer and Corresponding $90 \%$ Confidence Intervals (Cls) by Industrial Sector ${ }^{\mathrm{b}}$ of Longest Employment (During 1974-2009) ${ }^{\mathrm{C}}$, Lombardy, Italy, 2002-2009

\begin{tabular}{|c|c|c|c|c|c|}
\hline Industrial sector ${ }^{\mathrm{b}}$ (ATECO $81^{\mathrm{d}}$ code) & $\begin{array}{c}\text { Breast } \\
\text { cancer cases }\end{array}$ & Controls & OR (90\% Cl) & P-value & q-value ${ }^{e}$ \\
\hline Retail/wholesale trade and services ${ }^{\dagger}(611-619 ; 630 ; 640 ; 650 ; 653)$ & 3,154 & 9,189 & 1.00 (Reference) & & \\
\hline Iron and steel industry $(221-224 ; 311-312)$ & 132 & 261 & $1.17(0.98-1.40)$ & 0.151 & 0.394 \\
\hline Building products (241-243;245-246) & 11 & 30 & $0.87(0.48-1.55)$ & 0.683 & 0.802 \\
\hline $\begin{array}{l}\text { Mechanical manufacturing }(314-316 ; 319,321-328 ; 330 \text {; } \\
\quad 351-353 ; 362-363 ; 365 ; 371-374 ; 671)\end{array}$ & 1,019 & 2,253 & $1.06(0.99-1.14)$ & 0.159 & 0.394 \\
\hline Electrical manufacturing (342-348) & 822 & 1,709 & $1.12(1.04-1.21)$ & 0.018 & 0.271 \\
\hline Food industry (411-419; 421-423; 428) & 369 & 877 & $1.01(0.91-1.13)$ & 0.854 & 0.879 \\
\hline Textile industry (431-439) & 1,882 & 4,031 & $1.08(1.02-1.15)$ & 0.030 & 0.271 \\
\hline Leather and shoes industry $(441-442 ; 451-452 ; 672)$ & 372 & 840 & $1.03(0.92-1.15)$ & 0.640 & 0.802 \\
\hline Garment industry (453-456) & 1,690 & 3,700 & $1.07(1.01-1.14)$ & 0.076 & 0.394 \\
\hline Wood industry (461-467) & 186 & 501 & $0.87(0.76-1.01)$ & 0.129 & 0.394 \\
\hline Paper industry (471-472) & 177 & 335 & $1.25(1.06-1.46)$ & 0.021 & 0.271 \\
\hline Press industry (473-474) & 156 & 356 & $1.03(0.88-1.21)$ & 0.776 & 0.873 \\
\hline Rubber industry $(341 ; 481-482)$ & 106 & 196 & $1.26(1.03-1.54)$ & 0.062 & 0.394 \\
\hline Building industry (501-504) & 18 & 45 & $0.94(0.59-1.49)$ & 0.826 & 0.879 \\
\hline Petroleum industry $(131 ; 134 ; 140)$ & 4 & 6 & $1.57(0.54-4.54)$ & 0.488 & 0.694 \\
\hline Transport industry $(720 ; 750 ; 760 ; 770 ; 790)$ & 19 & 36 & $1.29(0.81-2.07)$ & 0.369 & 0.622 \\
\hline Chemical industry $(251 ; 255-256 ; 258-260)$ & 187 & 378 & $1.15(0.99-1.34)$ & 0.131 & 0.394 \\
\hline Agriculture (011) & 102 & 273 & $0.92(0.75-1.11)$ & 0.462 & 0.692 \\
\hline Electrical power and gas $(132 ; 161-163)$ & 1 & 10 & $0.25(0.05-1.42)$ & 0.189 & 0.394 \\
\hline Alcoholic beverages and wine production $(424-425 ; 427)$ & 13 & 19 & $1.61(0.89-2.91)$ & 0.189 & 0.394 \\
\hline Coal industry (120) & 3 & 2 & $3.52(0.78-15.82)$ & 0.168 & 0.394 \\
\hline Glass industry (247) & 24 & 71 & $0.78(0.53-1.15)$ & 0.293 & 0.565 \\
\hline Pottery industry (248) & 39 & 94 & $0.97(0.71-1.33)$ & 0.880 & 0.879 \\
\hline Pharmaceutical industry (257) & 102 & 224 & $1.08(0.88-1.32)$ & 0.534 & 0.720 \\
\hline Aircraft production (364) & 2 & 2 & $2.21(0.43-11.46)$ & 0.428 & 0.680 \\
\hline Plastic industry (483) & 319 & 809 & $0.94(0.84-1.05)$ & 0.356 & 0.622 \\
\hline Health care and veterinarian service (950) & 218 & 497 & $1.04(0.90-1.19)$ & 0.661 & 0.802 \\
\hline Dry cleaning sector (981) & 61 & 185 & $0.78(0.61-1.00)$ & 0.102 & 0.394 \\
\hline
\end{tabular}

${ }^{a}$ Composite model with all industrial sectors simultaneously considered, adjusted for age and province.

${ }^{\mathrm{b}}$ Classification of the industrial sectors provided in the Occupational Cancer Monitoring (OCCAM) project, with the corresponding categories in the ATEC0 81 system.

'Data on INPS archives are available from 1974.

${ }^{\mathrm{d}}$ Italian statistical classification of economic activities.

${ }^{\text {e}}$ Computed according to the Benjamini-Hochberg method.

fBlue-collar workers in retail/wholesale trade and services.

\section{DISCUSSION}

The present study identified modestly but statistically significant increased ORs in Lombardy for breast cancer among women employed in the electrical manufacturing, textile, garment, paper, or rubber industries. Analyses on duration for the sector of longest employment showed consistent results, pointing to a putative role for exposures in electrical manufacturing, garment and rubber industries in breast cancer risk. However, after the adjustment, we did not find any $q$-value lower than 0.05 .
All these industrial sectors could involve exposures to organic solvents and/or chemical compounds and, although our study did not allow for adjustments for confounders, it is possible that some of these substances could act as endocrine disruptors.

Some productive sectors with exposure to night shift work and/or ionizing radiation, such as flight transport and private health care services were grouped with transport and health care and veterinarian services, respectively, while vehicle manufacturing which entails exposure to paints, varnishes and other chemicals was grouped with mechanical manufacturing. 
TABLE V. Adjusted Odds Ratios $(\mathrm{ORs})^{\mathrm{a}}$ of Breast Cancer by Duration of Longest Employment (During 1974-2009) ${ }^{\mathrm{b}}$ and Corresponding $90 \%$ Confidence Intervals (Cls) by Industrial Sector ${ }^{\mathrm{C}}$, Lombardy, Italy, 2002-2009

\begin{tabular}{|c|c|c|c|c|}
\hline Industrial sector ${ }^{\mathrm{C}}\left(\right.$ Ateco $81^{\mathrm{d}}$ code) & Duration (years) & OR (90\% CI) & Pvalue & $q$ value $^{e}$ \\
\hline \multirow[t]{5}{*}{ Iron and steel industry (221-224; 311-312) } & $0-4$ & Reference & & \\
\hline & $5-9$ & $0.71(0.40-1.27)$ & 0.328 & 0.763 \\
\hline & $10-19$ & $0.78(0.46-1.31)$ & 0.427 & 0.763 \\
\hline & $20+$ & $1.22(0.72-2.07)$ & 0.528 & 0.763 \\
\hline & & $P$ for trend ${ }^{\dagger} 0.349$ & & \\
\hline \multirow{7}{*}{$\begin{array}{l}\text { Mechanical manufacturing (314-316; 319, } \\
\text { 321-328; 330; 351-353; 362-363; } \\
\text { 365; 371-374; 671) }\end{array}$} & $0-4$ & Reference & & \\
\hline & & & & \\
\hline & & & & \\
\hline & $5-9$ & $1.08(0.89-1.33)$ & 0.511 & 0.763 \\
\hline & $10-19$ & $1.16(0.96-1.41)$ & 0.184 & 0.763 \\
\hline & $20+$ & $1.11(0.92-1.34)$ & 0.366 & 0.763 \\
\hline & & $P$ for trend ${ }^{\dagger} 0.067$ & & \\
\hline \multirow[t]{5}{*}{ Electrical manufacturing (342-348) } & $0-4$ & Reference & & \\
\hline & $5-9$ & $1.04(0.82-1.33)$ & 0.796 & 0.910 \\
\hline & $10-19$ & $1.41(1.13-1.77)$ & 0.011 & 0.585 \\
\hline & $20+$ & $1.37(1.10-1.71)$ & 0.018 & 0.585 \\
\hline & & $P$ for trend ${ }^{\dagger} 0.003$ & & \\
\hline \multirow[t]{5}{*}{ Food industry (411-419; 421-423; 428) } & $0-4$ & Reference & & \\
\hline & $5-9$ & $1.28(0.91-1.40)$ & 0.239 & 0.763 \\
\hline & $10-19$ & $1.25(0.92-1.33)$ & 0.233 & 0.763 \\
\hline & $20+$ & $1.13(0.83-1.19)$ & 0.521 & 0.763 \\
\hline & & $P$ for trend 0.693 & & \\
\hline \multirow[t]{5}{*}{ Textile industry (431-439) } & $0-4$ & Reference & & \\
\hline & $5-9$ & $1.09(0.94-1.26)$ & 0.323 & 0.763 \\
\hline & $10-19$ & $1.09(0.95-1.25)$ & 0.300 & 0.763 \\
\hline & $20+$ & $1.13(0.98-1.29)$ & 0.146 & 0.678 \\
\hline & & $P$ for trend ${ }^{\mathrm{f}} 0.181$ & & \\
\hline \multirow[t]{5}{*}{ Leather and shoes industry $(441-442 ; 451-452 ; 672)$} & $0-4$ & Reference & & \\
\hline & $5-9$ & $1.08(0.79-1.47)$ & 0.684 & 0.899 \\
\hline & $10-19$ & $1.12(0.84-1.50)$ & 0.519 & 0.763 \\
\hline & $20+$ & $0.80(0.59-1.10)$ & 0.250 & 0.763 \\
\hline & & $P$ for trend 0.282 & & \\
\hline \multirow[t]{5}{*}{ Garment industry (453-456) } & $0-4$ & Reference & & \\
\hline & $5-9$ & $1.00(0.87-1.15)$ & 0.997 & 0.997 \\
\hline & $10-19$ & $1.07(0.94-1.23)$ & 0.390 & 0.763 \\
\hline & $20+$ & $1.16(1.01-1.34)$ & 0.090 & 0.650 \\
\hline & & $P$ for trend 0.060 & & \\
\hline \multirow[t]{5}{*}{ Wood industry (461-467) } & $0-4$ & Reference & & \\
\hline & $5-9$ & $1.25(0.81-1.94)$ & 0.391 & 0.763 \\
\hline & $10-19$ & $1.48(0.99-2.20)$ & 0.103 & 0.662 \\
\hline & $20+$ & $1.22(0.80-1.85)$ & 0.444 & 0.763 \\
\hline & & $P$ for trend ${ }^{\dagger} 0.342$ & & \\
\hline \multirow[t]{5}{*}{ Paper industry (471-472) } & $0-4$ & Reference & & \\
\hline & $5-9$ & $0.71(0.45-1.11)$ & 0.201 & 0.763 \\
\hline & $10-19$ & $0.77(0.51-1.17)$ & 0.304 & 0.675 \\
\hline & $20+$ & $0.67(0.44-1.04)$ & 0.135 & 0.763 \\
\hline & & $P$ for trend ${ }^{\dagger} 0.178$ & & \\
\hline
\end{tabular}


TABLE V. (Continued)

Industrial sector ${ }^{\mathrm{C}}$ (Ateco 81 ${ }^{\mathrm{d}}$ code)

Press Industry (473-474)

Rubber industry $(341 ; 481-482)$

Building industry (501-504)

Transport industry $(720 ; 750 ; 760 ; 770 ; 790)$

Chemical industry $(251 ; 255-256 ; 258-260)$

Agriculture (011)

Alcoholic beverages and wine production (424-425; 427)

Glass industry (247)

Pottery industry (248)

Pharmaceutical industry (257)
Duration (years)

OR $(90 \% \mathrm{CI})$

Pvalue

q value ${ }^{\mathrm{e}}$

$0-4$

5-9

$10-19$

$20+$

0-4

5-9

$10-19$

$20+$

0-4

5-9

10-19

$20+$

0-4

5-9

10-19

$20+$

$0-4$

5-9

10-19

$20+$

$0-4$

5-9

10-19

$20+$

0-4

5-9

10-19

$20+$

0-4

5-9

10-19

$20+$

$0-4$

5-9

$10-19$

$20+$

0-4

$5-9$

10-19

$20+$

Reference

$1.06(0.66-1.70)$

0.838

0.580

0.763

$0.92(0.57-1.48)$

$P$ for trend 0.836

Reference

2.81 (1.23-6.39)

0.039

0.089

0.034

$2.71(1.25-5.87)$

$P$ for trend ${ }^{\dagger} 0.128$

Reference

$1.12(0.36-3.49)$

$0.48(0.14-1.70)$

$1.45(0.28-7.59)$

$P$ for trend ${ }^{\dagger} 0.715$

$$
\text { Reference }
$$

$1.29(0.41-4.06)$

$1.15(0.34-3.93)$

0.719

0.875

0.341

0.714

0.923

0.675

0.899

$P$ for trend ${ }^{\dagger} 0.440$

Reference

$1.14(0.67-1.95)$

0.682

0.528

0.899

$1.19(0.76-1.87)$

0.135

0.763

$1.52(0.96-2.42)$

0.650

$P$ for trend ${ }^{\dagger} 0.120$

$$
\text { Reference }
$$

$0.80(0.52-1.24)$

0.407

0.763

$0.65(0.31-1.38)$

0.347

0.675

$P$ for trend ${ }^{\dagger} 0.300$

Reference

$$
0.72(0.07-7.03)
$$

0.812

0.978

0.910

$0.98(0.24-4.04)$

0.718

0.993

$1.46(0.26-8.10)$

$P$ for trend ${ }^{\dagger} 0.950$

Reference

$0.71(0.23-2.21)$

0.619

0.508

0.935

0.856

$1.51(0.55-4.16)$

$0.95(0.32-2.79)$

$P$ for trend $d^{\dagger} 0.799$

Reference

$0.34(0.13-0.87)$

0.060

0.290

0.443

$0.57(0.23-1.37)$

$0.64(0.25-1.66)$

$P$ for trend ${ }^{\dagger} 0.761$

Reference

$1.16(0.56-2.42)$

$1.03(0.55-1.91)$

0.737

0.938

0.478

0.904

0.968

0.763

$P$ for trend ${ }^{\dagger} 0.499$ 
TABLE V. (Continued)

\begin{tabular}{|c|c|c|c|c|}
\hline Industrial sector ${ }^{\mathrm{C}}$ (Ateco $81^{\mathrm{d}}$ code) & Duration (years) & OR (90\% CI) & $P$ value & $q$ value $e^{e}$ \\
\hline \multicolumn{5}{|l|}{ Plastic industry (483) } \\
\hline & $0-4$ & Reference & & \\
\hline & $5-9$ & $0.85(0.61-1.17)$ & 0.393 & 0.763 \\
\hline & $10-19$ & $0.72(0.53-0.98)$ & 0.083 & 0.650 \\
\hline & $20+$ & $0.69(0.50-0.96)$ & 0.061 & 0.650 \\
\hline & & $P$ for trend $d^{\dagger} 0.042$ & & \\
\hline \multirow[t]{5}{*}{ Health care and veterinarian service (950) } & $0-4$ & Reference & & \\
\hline & $5-9$ & $1.19(0.78-1.83)$ & 0.498 & 0.763 \\
\hline & $10-19$ & $1.32(0.90-1.93)$ & 0.238 & 0.763 \\
\hline & $20+$ & $1.07(0.70-1.62)$ & 0.799 & 0.910 \\
\hline & & $P$ for trend 0.699 & & \\
\hline \multirow[t]{5}{*}{ Dry cleaning sector (981) } & $0-4$ & Reference & & \\
\hline & $5-9$ & $0.70(0.37-1.30)$ & 0.333 & 0.763 \\
\hline & $10-19$ & $1.29(0.69-2.41)$ & 0.502 & 0.763 \\
\hline & $20+$ & $2.29(0.97-5.41)$ & 0.112 & 0.662 \\
\hline & & $P$ for trend ${ }^{\dagger} 0.140$ & & \\
\hline
\end{tabular}

${ }^{a}$ Compositemodel withall industrial sectors simultaneously considered, adjusted for age, provinceand latency. No estimates were provided for duration in aircraft production, electrical power and gas, petroleum industry and building products because small numbers led to some strata with no cases and/or controls.

${ }^{\mathrm{b}}$ Data on INPS archives are available from 1974.

${ }^{\circ}$ Classification of the industrial sectors provided in the 0ccupational Cancer Monitoring (OCCAM) project, with the corresponding categories in the ATEC0 81 system.

${ }^{\mathrm{d}}$ Italian statistical classification of economic activities.

${ }^{\text {e}}$ Computed according to the Benjamini-Hochberg method.

${ }^{\mathrm{f}} P$-value for linear trend.

Specific details for each industrial sector are presented in the following sections.

\section{Electrical Manufacturing Industry}

Our results showed a $12 \%$ increased OR of breast cancer in electrical manufacturing and a significant trend in risk by duration.

Electrical manufacturing is a complex industrial sector, in which rather different processes may be carried out, entailing different exposures. Some of the factories included in this sector produce electronic equipment and their women workers might be exposed to precision welding work, involving lead alloy or organic solvents. An increased risk of breast cancer in this industrial sector was recently observed [Peplonska et al., 2007; Sung et al., 2007], especially in "blue collar" workers [Peplonska et al., 2007].

Exposures to electromagnetic fields in this sector may also occur, although the literature is inconsistent with regard to breast cancer [Erren, 2001]. No association has been found with exposure to extremely low-frequency electromagnetic fields [Chen et al., 2010].

\section{Textile and Garment Industry}

Our results point to a $7 \%$ increased OR in the garment industry and to a similar $8 \%$ increase in the textile industry.
Women involved in these industrial sectors could be exposed to dusts, jelling and lubricant chemical agents, dyes, fixatives and organic solvents. Moreover, some textile factories, mainly in the past, adopted a form of work organization that included night and shift work. Some of these exposures could act as endocrine disruptors, and might thus play a role in female breast cancer risk via promotional mechanisms as well as by affecting mammary gland development and responsiveness to other carcinogens [Brody and Rudel, 2003].

According to the International Agencyfor Research on Cancer (IARC), working in the textile manufacturing industry entails exposures to some carcinogenic agents in the 2B group [IARC, 1990].

There is some evidence from elsewhere for a role of these industrial sectors [Lynge and Thygesen, 1990; Simpson et al., 1999; Kuzmickiene et al., 2004; Villeneuve et al., 2011], although some large studies have found no association with female breast cancer in women employed as textile workers [Ray et al., 2007].

\section{Paper Industry}

Our results suggested a $25 \%$ increased OR for female breast cancer in this sector, although no association was found with duration of employment.

Paper production can expose women workers to acrylamide (IARC 2A Group), epichlorodhydrin (IARC 2A 
Group), formaldehyde (IARC 1 Group) or some other chemical compounds used as dyes or bleaching, but it is difficult to define the role of those substances in breast cancer risk.

A non-statistical significant association between employment in the paper industry and female breast cancer was found elsewhere, in a cohort study by Sala-Serra et al. [1996] (standardized mortality ratio, SMR 286, 95\% CI 77-732), whereas no association was found in recent published studies conducted on workers in paper and pulp industry.

\section{Rubber Industry}

A $26 \%$ increased OR emerged from our analyses on never/ever exposure to rubber industry as the sector of longest duration. Duration analyses showed also a significant increased risk in all classes, although without a significant trend.

In the rubber industry, a variety of chemical substances are employed across several production steps, including the vulcanization process; among others, different kinds of synthetic rubber, solvents (heptanes, toluene, and methyl ethyl ketone) and additives may be relevant. These chemical compounds could have impurities or be polluted by others substances, (possibly more hazardous, and release fumes and vapors, especially during the hot processing steps.

Several studies have not found increased risks of female breast cancer for this sector [Solionova and Smulevich, 1993; Simpson et al., 1999; Sathiakumar and Delzell, 2009], except for exposure to styrene, a chemical compound largely present in rubber processing [Cantor et al., 1995]. However, de Vocht et al. [2009] showed an exposure-response association with breast cancer in women exposed to aromatic amines in a rubber tyre manufacturing plant.

\section{Study Strengths and Limitations}

The use of administrative data collected by institutional subjects (Lombardy Region and INPS) is both an advantage and a disadvantage in a case-control study.

From one side, it reduces time and costs of the study and allows one to have a standardized classification of the disease, as well as of the industrial sectors in which cases and controls worked.

On the other hand, the study base was not created for scientific or research purposes and the classification of diagnostic codes and occupational exposures may be insufficiently detailed.

These shortcomings probably did not affect this study severely: $97,2 \%$ of incident cases of female breast cancer identified form the Varese province cancer registry in 20022005 were also correctly identified from the corresponding hospital discharge records in the same province and time period. However, a similar check on exposure data was not possible.

We are aware that analyses at the level of industrial sector, without extra information on occupation and tasks may be crude. However, we restricted our analyses to "blue collar" women, as directly defined by INPS. This should help us to identify those women who are more likely to be exposed to productive processes and potentially to some carcinogens.

Missing information on potential confounders could be a severe limitation of the study. Questionnaires or interviews eliciting information on genetic factors, socioeconomic status, dietary habits, alcohol, and medication use, reproductive history or physical activity were not part of this exploratory study. We tried to limit confounding by restricting the analysis to "blue collar" workers.

Due to the limits of the INPS database, the analysis was restricted to women employed at least one year in the private sector between 1974 and 2009. Therefore, we did not have the opportunity to collect data on occupational histories before 1974. In order to reduce the impact of this limitation on our results, we performed our analysis on women aged 35-69 years at diagnosis.

Women working only in the public sector or who had have never worked or were only "white collar" workers were not included in the analysis.

Working women in a sector such as retail sales occupations and/or other sales occupations contributing to the "unexposed" category in this study have been reported to elevate risks for breast cancer [Peplonska et al., 2007]. Given the absence of information about potential confounders, an underestimate of the effects of occupational exposures on breast cancer might have resulted in this study as a result of their use as controls.

We performed analyses on duration of employment adjusting for latency using 5- and 10-year time lags. These results are notable for their consistency with those on sectors of longest duration, but they should be considered with caution. Our data suffer from left truncation, as occupational data are available only after 1974 . This exclusion may have ended up in a loss of years of exposure, especially for older subjects.

Correction for multiple comparisons is important for a sound statistical analysis, and is useful in the interpretation of results and in future study planning. We considered several adjustment techniques that are now available to deal with this issue [Benjamini and Hochberg, 1995; Shaffer, 1995; Benjamini and Yekutieli, 2001]. When we applied one of these to our data, none of the associations reached statistical significance. However, this study, similarly to that of Villeneuve et al. [2011], was aimed at achieving an overview of selected occupational risk factors for breast cancer and at providing the basis for more specific etiological hypotheses. Therefore, we presented and commented on results both adjusted and unadjusted for multiple comparisons. 


\section{CONCLUSIONS}

In the absence of adjustment for multiple comparisons, the present study showed a slightly increased but significant OR of female breast cancer in Lombardy after employment in the electrical construction, paper, rubber, textile, and garment industries.

Analyses on duration of employment showed increased ORs in the rubber industry and in electrical manufacturing and, for the last sector, also a significant linear trend.

Since occupational groups such as retail sales and/or other sales occupations contributed to the reference category in the present analysis and have been reported to have higher risks for breast cancer [Peplonska et al., 2007], this could have led to underestimate the effects of occupational exposures.

Our findings deserve further investigation, specifically to reach a better definition of the exposures potentially involved in those productive sectors where we observed increased ORs. We have already set up an in-depth study in collaboration with a major Italian company in the electrical manufacturing industry, to provide an industry-based casecontrol study and to enable insight into the company's production processes and the workforce's occupational tasks, potential exposures to chemical compounds, and some relevant confounders.

\section{ACKNOWLEDGMENTS}

The authors thank Prof. Stefano Mattioli and Dr. Dario Mirabelli for their revision of the article and their suggestions. This study was partially supported by the Master in Epidemiology of the University of Turin and by the San Paolo Foundation.

\section{REFERENCES}

Aiani MR, Bai E, Oddone E, Settimi L, Genna G, Maternini P, Scaburri A, Panizza C, Crosignani P. 2011. From research on occupational tumors to interventional prevention: Use of the OCCAM method at the ASL in Como. G Ital Med Lav Ergon 33(4):381-386.

Benjamini Y, Hochberg Y. 1995. Controlling the false discovery rate: A practical and powerful approach to multiple testing. J R Stat Soc B $57: 289-300$

Benjamini Y, Yekutieli D. 2001. The control of the false discovery rate in multiple testing under dependency. Ann Stat 29:1165-1188.

Brody JG, Rudel RA. 2003. Environmental pollutants and breast cancer. Environ Health Perspect 111(8):1007-1019.

Cantor KP, Stewart PA, Brinton LA, Dosemeci M. 1995. Occupational exposures and female breast cancer mortality in the United States. J Occup Environ Med 37(3):336-348.

Chen C, Ma X, Zhong M, Yu Z. 2010. Extremely low-frequency electromagnetic fields exposure and female breast cancer risk: A meta- analysis based on 24,338 cases and 60,628 controls. Breast Cancer Res Treat 123(2):569-576.

Commentary. 2009. Breast cancer on the night shift. Lancet 373:1054.

Crosignani P, Massari S, Audisio R, Amendola P, Cavuto S, Scaburri A, Zambon P, Nedoclan G, Stracci F, Pannelli F, Vercelli M, Miligi L, Imbriani M, Berrino F. 2006. The Italian surveillance system for occupational cancers: Characteristics, initial results and future prospects. Am J Ind Med 49(9):791-7918.

Davis DL, Axelrod D, Bailey L, Gaynor M, Sasco AJ. 1998. Rethinking breast cancer risk and the environment: The case for the precautionary principle. Environ Health Perspect 106:523-529.

de Vocht F, Sobala W, Wilczynska U, Kromhout H, SzeszeniaDabrowska N, Peplonska B. 2009. Cancer mortality and occupational exposure to aromatic amines and inhalable aerosols in rubber tire manufacturing in Poland. Cancer Epidemiol 33(2):94-102.

Erren TC. 2001. A meta-analysis of epidemiologic studies of electric and magnetic fields and breast cancer in women and men. Bioelectromagnetics (Suppl 5):S105-S119.

Grosse Y, Baan R, Straif K, Secretan B, El Ghissassi F, Bouvard V, Benbrahim-Tallaa L, Guha N, Galichet L, Cogliano V. 2009. WHO International agency for research on cancer monograph working group. A review of human carcinogens-part A: Pharmaceuticals. Lancet Oncol $10: 13-14$

International Agency for Research on Cancer (IARC). 1987. IARC monographs on the evaluation of carcinogenic risks to humans supplement 7. Overall evaluations of carcinogenicity: An updating of IARC monographs. Vol 1-42. Lyon: International Agency for Research on Cancer.

International Agency for Research on Cancer (IARC). 1990. IARC monographs on the evaluation of carcinogenic risks to humans. Lyon: International Agency for Research on Cancer.

International Agency for Research on Cancer (IARC). 1999. IARC monographs on the evaluation of carcinogenic risks to humans. Hormonal contraception and post-menopausal hormone therapy. Vol. 72. Lyon: International Agency for Research on Cancer.

International Agency for Research on Cancer (IARC). 2002. IARC handbooks of cancer prevention. Weight control and physical activity. Vol. 6. Lyon: International Agency for Research on Cancer 2002.

International Agency for Research on Cancer (IARC). 2003. IARC handbooks of cancer prevention. Fruit and vegetables. Vol. 8. Lyon: International Agency for Research on. Cancer 2003.

International Agency for Research on Cancer (IARC). 2012. IARC monographs on the evaluation of carcinogenic risks to humans. E: lifestyle factors. Vol. 100. Lyon: International Agency for Research on Cancer 2012

Jemal A, Center MM, DeSantis C, Ward EM. 2010. Global patterns of cancer incidence and mortality rates and trends. Cancer Epidemiol Biomarkers Prev 19:1893-1907.

Kuzmickiene I, Didziapetris R, Stukonis M. 2004. Cancer incidence in the workers cohort of textile manufacturing factory in Alytus, Lithuania. J Occup Environ Med 46(2):147-153.

Labrèche F, Goldberg MS, Valois MF, Nadon L. 2010. Postmenopausal breast cancer and occupational exposures. Occup Environ Med 67 (4):263-269.

Lynge E, Thygesen L. 1990. Occupational cancer in Denmark. Cancer incidence in the 1970 census population. Scandj Work Environ Health 16(suppl 2):7-35.

Panizza C, Bai E, Oddone E, Scaburri A, Massari S, Modonesi C, Contiero P, Marinaccio A, Crosignani P. 2012. Lung cancer risk in the electroplating industry in Lombardy, Italy, using the Italian 
Occupational Cancer Monitoring (OCCAM) information system. Am J Ind Med 55(1):1-4.

Peplonska B, Stewart P, Szeszenia-Dabrowska N, Rusiecki J, GarciaClosas M, Lissowska J, Bardin-Mikolajczak A, Zatonski W, Gromiec J, Brzeznicki S, Brinton LA, Blair A. 2007. Occupation and breast cancer risk in Polish women: A population-based case-control study. Am J Ind Med 50(2):97-111.

R Development Core Team. 2011. R: A language and environment for statistical computing. Vienna, Austria: R Foundation for Statistica Computing. $2010 \mathrm{http} / / / w w w . R-p r o j e c t . o r g ~(31$ December 2011, date last accessed)

Ray RM, Gao DL, Li W, Wernli KJ, Astrakianakis G, Seixas NS, Camp JE, Fitzgibbons ED, Feng Z, Thomas DB, Checkoway H. 2007. Occupational exposures and breast cancer among women textile workers in Shanghai. Epidemiology 18:383-392.

Rushton L, Bagga S, Bevan R, Brown TP, Cherrie JW, Holmes P, Fortunato L, Slack R, Van Tongeren M, Young C, Hutchings SJ. Occupation and Cancer in Britain. Br J Cancer 2010. 102(9): 1428-1437.

Sala-Serra M, Sunyer J, Kogevinas M, McFarlane D, Antó JM. 1996. Cohort study on cancer mortality among workers in the pulp and paper industry in Catalonia, Spain. Am J Ind Med 30(1):87-92.

Sathiakumar N, Delzell E. 2009. A follow-up study of mortality among women in the North American synthetic rubber industry. J Occup Environ Med 51(11):1314-1325.

Secretan B, Straif K, Baan R, Grosse Y, El Ghissassi F, Bouvard V, Benbrahim-Tallaa L, Guha N, Freeman C, Galichet L, Cogliano V. 2009.
WHO International agency for research on cancer monograph working group. A review of human carcinogens-Part E: Tobacco, areca nut, alcohol, coal smoke, and salted fish. Lancet Oncol 10:10331034

Shaffer JP. 1995. Multiple hypothesis testing. Ann Rev Psychol 46:561576.

Simpson J, Roman E, Law G, Pannett B. 1999. Women's occupation and cancer: Preliminary analysis of cancer registrations in England and Wales, 1971-1990. Am J Ind Med 36(1):172-185.

Solionova LG, Smulevich VB. 1993. Mortality and cancer incidence in a cohort of rubber workers in Moscow. Scand J Work Environ Health 19 (2):96-101.

Sung TI, Chen PC, Jyuhn-Hsiarn Lee L, Lin YP, Hsieh GY, Wang JD. 2007. Increased standardized incidence ratio of breast cancer in female electronics workers. BMC Public Health 7:102.

Villeneuve S, Févotte J, Anger A, Troung T, Lamkarkach F, Gaye O, Kerbat P, Arveux P, Miglianico L, Imbernon E, Guénel p. 2011. Breast cancer risk by occupation and industry: Analysis of the CECILE study, a population-based case-control study in France. Am J Ind Med 54:499_ 509.

Weiderpass E, Meo M, Vainio H. 2011. Risk factors for breast cancer, including occupational exposures. Saf Health Work 2(1):1-8.

Ziegler RG, Hoover RN, Pike MC, Hildesheim A, Nomura AMY, West DW, Wu-Williams AH, Kolonel LN, Horn-Ross PL, Rosenthal JF, Hyer MB. 1993. Migration patterns and breast cancer risk in Asian-American women. J Natl Cancer Inst 85:1819-1827. 